\title{
ARTIGOORIGINAL
}

\section{CENA DE UM ENCONTRO PSICODRAMÁTICO NA PROMOÇÃO DO EMPODERAMENTO FEMININO COM UM GRUPO DE MULHERES UNIVERSITÁRIAS}

DOI: 10.22289/2446-922X.V6N2A21

Gilmar Antoniassi Junior ${ }^{1}$ Glória Lúcia Alves Figueiredo Regina Celia de Souza Beretta

\section{RESUMO}

Este artigo tem como proposta relatar a cena de um encontro psicodramático com mulheres universitárias na promoção do empoderamento feminino. Foram realizados dez encontros com 18 participantes em fase de conclusão do curso, onde a prática embasou-se no uso das técnicas do psicodrama. O relato objetiva narrar umas das cenas vivenciadas num grupo de psicodrama com mulheres universitárias do interior do estado de Minas Gerais, Brasil, visando a promoção do empoderamento feminino, demonstrando o quanto as sessões psicodramáticas podem dar autonomia às mulheres para se expressarem em sua dimensão social.

Palavras-chave: Mulheres; Psicodrama; Empoderamento Feminino.

\section{SCENE OF A PSYCHODRAMATIC ENCOUNTER TO PROMOTE FEMALE EMPOWERMENT WITH A GROUP OF UNIVERSITY WOMEN}

\section{ABSTRACT}

This article aims to report the scene of a psychodramatic encounter with university women in the promotion of female empowerment. Ten meetings were held with 18 participants at the conclusion of the course, where the practice was based on the use of psychodrama techniques. The report aims to narrate one of the scenes experienced in a group of psychodrama with university women from the interior of the state of Minas Gerais, Brazil, aiming at promoting female empowerment, demonstrating how much psychodramatic sessions can empower women to express themselves in their social dimension.

Keywords: Women; Psychodrama; Female Empowerment.

\footnotetext{
${ }^{1}$ Endereço eletrônico de contato: jrantoniassi@hotmail.com

Recebido em 24/09/2020. Aprovado pelo conselho editorial para publicação em 26/10/2020.
}

Rev. Psicol Saúde e Debate. Dez., 2020:6(2): 328-337. 


\section{ESCENA DE UN ENCUENTRO PSICODRAMÁTICO PARA PROMOVER EL EMPODERAMIENTO FEMENINO CON UN GRUPO DE MUJERES UNIVERSITARIAS}

\section{RESUMEN}

Este artículo tiene como objetivo reportar el escenario de un encuentro psicodramático con mujeres universitarias en la promoción del empoderamiento femenino. Se realizaron diez reuniones con 18 participantes al finalizar el curso, donde la práctica se basó en el uso de técnicas de psicodrama. El informe tiene como objetivo narrar una de las escenas vividas en un grupo de psicodrama con mujeres universitarias del interior del estado de Minas Gerais, Brasil, con el objetivo de promover el empoderamiento femenino, demostrando cuánto las sesiones psicodramáticas pueden empoderar a las mujeres para expresarse en su dimensión social.

Palabras clave: Mujeres; Psicodrama; Empoderamiento de Las Mujeres.

\section{INTRODUÇÃO}

Muito tem se discutido sobre ser mulher na atualidade e a sua 'emancipação', ou seja, a liberdade da mulher num espaço e tempo. No Brasil, segundo dados do IBGE (2020), estima-se que exista o percentual de $51,8 \%$ de mulheres, quase quatro milhões a mais em relação à quantidade de homens, cujo percentual é de $48,2 \%$.

Desde o movimento feminista tal como outros movimentos sociais, o protagonismo das mulheres tem revelado que o debate de que as mulheres mesmo em cenários adversos e desiguais quanto ao contexto da cidade nas quais vivem e abraçam, por sua capacidade maternal associada à sua biografia, denotam para a necessidade de cuidar e lutar pelo direito e a igualdade de gênero na sociedade (Brandão et al., 2018; Paes, 2016; World Health Organization, 2016).

A mulher submissa foi trocada pela mulher múltipla, onde nos dias atuais a representação de papeis por parte dessa mulher, está em cuidar da casa, filhos e marido, trabalhar fora e ainda adequar seu tempo a cuidar de si, aperfeiçoar em cursos e manter o seu kit beleza do dia a dia, sendo que é impossível por razões fisiológicas e financeiras que todas as mulheres pudessem ocupar esse lugar, causando a sensação de incompletude. O caminho que tem que ser percorrido entre o espaço homem e mulher é o principal mantenedor de conflitos emocionais que perdura esse convívio (Freire Filho \& Leal, 2015).

Vale ressaltar que os papeis sociais de homem de mulher não foram ocupados de forma natural, mas com braveza de subjugação, o lugar onde cada gênero se coloca é que se tornou natural. Por conseguinte, as mulheres ocupam $55,1 \%$ das vagas das universidades no Brasil e somam 58,8\% daqueles que concluíram o curso superior, representando ainda 53,5\% dos profissionais com a titulação de mestre, fazendo com que a qualificação das mulheres chame

Rev. Psicol Saúde e Debate. Dez., 2020:6(2): 328-337. 
atenção das organizações de recrutamento e seleção do país. Contudo, sabe-se que a presença feminina em cargos de gerência e tomada de decisões, tanto em âmbito público como no privado, é de apenas 39,1\% (IBGE, 2016). Embora, as mulheres sejam as que mais recorrem ao ensino superior em busca de qualificação, elas são as que recebem cerca de $30 \%$ a menos de salário que os homens e, possivelmente, por receio dos filhos e da família interferirem em seu desempenho profissional, algumas empresas evitam contratá-las (IBGE, 2018; Brandão et al., 2018).

A participação da mulher no setor público brasileiro denota para representação destas ante a necessidade da criação e manutenção de políticas que atendam à essas demandas, contudo, a representatividade feminina na esfera política é de apenas $7,1 \%$ relativa à ocupação em cargos políticos se comparados aos homens em cargos ministeriais do governo, o que embora seja uma representação diminuta, já é um marco e conquista diante da trajetória e busca pela emancipação política e social feminina (IBGE, 2016).

A presença feminina segue cada vez mais evidente em muitas situações nas quais representam o principal suporte financeiro familiar. Isso significa que, além da maternidade, a mulher passou a assumir com mais intensidade as responsabilidades no contexto familiar (Simões \& Hashimoto, 2012), resultando, de modo inegável e inevitável, em mudanças de posições em diferentes contextos da vida. Dado isso, o presente relato justifica-se pela viabilidade de demonstrar como o processo grupal, por meio das intervenções do psicodrama, pode contribuir para o empoderamento feminino. Logo, o relato objetiva narrar umas das cenas vivenciadas num grupo de psicodrama com mulheres universitárias, visando a promoção do empoderamento feminino, por meio da experiencia vivenciada a partir de uma narrativa de uma das cenas dos dez encontros psicodramáticos.

\section{ATÉ MAIS! Cena do encontro de fechamento do grupo de mulheres}

grupo foi composto por 18 mulheres universitárias, as quais estavam em fase final de conclusão de curso, com idade entre 21 a 41 anos, em sua maioria solteiras e entre elas algumas sendo mães (7 participantes). Foram realizados dez encontros, decorrendo das etapas equivalentes às sessões de psicodrama, respeitando, segundo Wechsler e Monteiro (2016), a possibilidade de o psicodrama resgatar o sujeito apoiado no aqui e agora, propiciando transformações e resgates de sua essência por percepção do seu cotidiano a partir dos papeis desempenhados.

Para isso, é importante assinalar que a origem da intervenção psicodramática está no princípio da espontaneidade, ou seja, na união do ser espontâneo com a representação teatral, conforme orientado por Moreno (2011), a observar os movimentos comportamentais dos participantes (atores) ligados nas cenas improvisadas a partir do seu eu vivencial. Os encontros

Rev. Psicol Saúde e Debate. Dez., 2020:6(2): 328-337. 
ocorriam semanalmente fora do ambiente acadêmico em um espaço amplo, arejado e de fácil acesso às participantes, tendo sido acordado no primeiro encontro conforme a disponibilidade do grupo.

Nessa oportunidade, seguiremos com o relato do décimo encontro denominado como o encontro do "ATÉ MAIS!". A finalidade do encontro era de que as participantes pudessem trazer para a reunião os aspectos que marcaram suas experiências no grupo, e assim, pudessem compartilhar, para que no final o encontro fosse encerrado com uma mensagem, e então seguirem em frente.

O encontro iniciou com a atividade de aquecimento. Naquele momento, o grupo já não tinha mais receios e estava pleno e coeso, mas visivelmente sensível pelo fato de ser o último encontro.

Enquanto as participantes iam chegando e adentrando à sala, era possível se ouvir: "Porque tem de acabar?"; "Este tempo que ficamos juntos me fez perceber que a vida é para ser vivida... não sou mais a mesma"; "Foi muito bom viver tudo isso aqui."; "Estou mais decidida e confiante em mim para o caminho a seguir"; de certo modo, o grupo dava sinais de que algo havia se modificado internamente a elas.

Assim que todas já estavam presentes, o diretor deu início a sessão:

Diretor: "Hoje é nosso último encontro, não será uma despedida, mas um até breve... Vamos todos ficar de pé e sentir a música... deixe a música tocar você... permita seu corpo expressar... sinta-se... fique livre no espaço... tome ele... feche seus olhos e sinta a música, sinta seu corpo".

No espaço dramático, o palco estava tomado por uma fresta de luz, para que este momento fosse de intimidade da mulher para mulher. As músicas selecionadas pelo diretor para 0 aquecimento inespecífico eram melodias que pudessem embalar as mulheres a se libertar e movimentar o corpo. Naquele momento, após nove encontros, elas já estavam mais sensibilizadas aos jogos sem muitas conservas que as impedissem de seguir o comando dado pelo diretor. Após 15 minutos de movimento corporal, foi proposto a cada uma delas que buscassem um local no palco que elas pudessem continuar com a sensação de liberdade e bem à vontade. Enquanto elas se acomodavam, uma cabine era posicionada no centro do palco e o ego auxiliar, que estava no interior sem que elas o vissem, segurava nas mãos um espelho.

Logo que todos estavam acomodados, com um fundo musical instrumental o diretor fala: "agora vocês vão pensar um pouquinho, ficar bem tranquilas, fechem os olhos, procurem ficar ao máximo confortável nas cadeiras, e vão começar a sentir a música, vocês vão se atentar ao meu comando", e em sequência orienta para exercício de respiração para que pudessem ficar em relaxamento profundo; após uns três minutos, o diretor dá sequência com a proposta de um relaxamento indutivo.

Rev. Psicol Saúde e Debate. Dez., 2020:6(2): 328-337. 
Diretor: "Você está deitado sobre essa nuvem e consegue ver bem a paisagem lá de baixo, os rios, os campos, o verde das plantas, as plantações e o mar, você sente a brisa gostosa, o calor do sol e continua seu passeio sobre as nuvens. Você vê as paisagens, as pessoas... você desce da nuvem, e começa a andar olhando tudo ao seu redor. Como é essa cidade? O que você observa? O que é importante? O que faz sentido?"; e é proposto à elas que façam um encontro, "pode continuar onde vocês estão de olhos fechados, atentas aos questionamentos, e eu vou conduzir uma por uma naquela cabine, lá vocês terão uns minutinhos, cada uma no seu tempo, tá certo?", e uma por uma era conduzida até lá.

$\mathrm{Na}$ cabine havia uma cadeira. Ao entrar, a participante era orientada pelo ego auxiliar a sentar-se; não era possível visualizar o ego auxiliar que estava atrás de uma cortina de teatro de fantoches, porém, a cortina ficava muito próxima da cadeira disponibilizada para as participantes.

Ego-auxiliar: "Olá, sente-se! E me diga seu nome".

Participantes: "Meu nome é..."

Ego-auxiliar: "Eu tenho algo aqui comigo, você deseja que Ihe mostre?"

Participantes: "Sim!"

Ego-auxiliar: "Oh (nome da participante), eu estou com uma imagem aqui, que quero te mostrar, e quando você ver essa imagem, eu gostaria que você falasse algo para ela. Pode ser? Vamos lá... A imagem é essa aqui, oh!".

Assim que a participante concordava, o ego-auxiliar mostrava um espelho, bem rente ao seu rosto. Muitas se assustavam ao verem a sua imagem, sendo impactante para muitas. Algumas, porém, arriscavam timidamente a dizer algo. Diziam que se achavam: "mais bonitas, inteligentes, esforçadas e lutadoras". Logo após as respostas, o ego-auxiliar indagava um segundo questionamento.

Ego-auxiliar: "Esta imagem te inspira?".

Foram várias as respostas, tais como: “Ah... uma imagem que já passou por muitas dificuldades, mas que continua na luta..."; "Uma pessoa ansiosa, mas que aprendeu a lidar com as coisas da sua vida..."; "Inspira confiança, amor e fé..."; "Inspira uma guerreira que vai se formar, eu vou transformar o mundo...".

Pareciam serem perguntas simples, porém algumas participantes tiveram dificuldade em responder, ficavam olhando aquela imagem refletida no espelho, abaixavam a cabeça, como se Rev. Psicol Saúde e Debate. Dez., 2020:6(2): 328-337. 
tivessem se negando a olhar. Para estas participantes, era dito pelo ego-auxiliar: "Fale com esta imagem... o que você diria a ela?", teve uma participante que começou a chorar e, embora com dificuldade, disse: "Calma... vai passar!!! Você é forte... e sabe o que fazer".

Após uma por uma passar pela cabine e retornar ao seu lugar, foi proposto pelo diretor abrir a roda de conversa e compartilhar.

Diretor: "E aí, como foi o encontro na cabine?".

As respostas se oscilaram entre a dificuldade e a facilidade de se reconhecer, e a participante aqui chamada de Flor, pontuou:

Flor: "Por mais difícil que seja olhar para nós mesmas na imagem refletida no espelho, eu tive a certeza que eu posso chegar onde eu quiser chegar, que ninguém mais me segura".

A fala de Flor tomou a emoção do grupo, e uma por uma, com a voz livremente alta, embarcam a dizer: "Eu também". Enquanto uma por vez de modo espontâneo dizia eu também, quando a última participante indagou, Flor propôs que todas se abraçassem e juntas emanassem a palavra "vitória".

O diretor aproveita o momento, como todas estão abraçadas, e propõe a dizer: "Para você o que foi participar deste grupo? Diga uma palavra que representa".

Participante 1. "Libertador".

Participante 2. "Vida".

Participante 3. "Renovação".

Participante 4. "Crer em mim".

Participante 5. "Fortaleza".

Participante 6. "Vitória".

Participante 7. "Foco".

Participante 8. "Esperança”.

Participante 9. "Transformação".

Participante 10. "Plenitude".

Participante 11. "Possibilidade".

Participante 12. "Regeneração".

Participante 13. "Aprimoramento".

Participante 14. "Fé".

Participante 15. "Motivador".

Rev. Psicol Saúde e Debate. Dez., 2020:6(2): 328-337. 
Participante 16. "Sucesso".

Participante 17. "Confiança".

Participante 18. "Autonomia".

Diretor: "Respeito".

Fecha-se a cortina da cena encerrando o grupo com todas as participantes cantando, dançando em forma de trenzinho, ao som da música alta, para agora continuarem a atuar pelos palcos da vida, exercendo seus papéis e fortemente enfrentando os scripts que vida trouxer.

\section{DIALOGANDO SOBRE O GRUPO}

O psicodrama ajudou as mulheres a entrar na visão da vida e nos sentimentos das outras participantes, incluindo o conhecimento de culturas e papeis bem diferentes na sociedade. Ele ampliou e aprofundou a experiência de todas; trazendo um maior reconhecimento dos valores e atitudes dos outros, e uma maior compreensão da estrutura de grupos e subculturas.

No psicodrama, o indivíduo se vê em estágios, progride em autorreconhecimento e aproveita a oportunidade para reavaliar a condição quando ele percebe aquele mesmo estágio por diferentes ângulos ou a partir do ponto de vista de outros.

Além disso, segundo Erigüç e Kose (2013), o psicodrama melhora a empatia, a qual é uma das muitas formas de habilidades eficazes e especialmente relevantes durante os encontros psicodramáticos.

O despertar da empatia é mais provável entre os membros da mesma comunidade moral. Porém, com o psicodrama, o desenvolvimento da empatia se expande através do desempenho e inversão de papéis, e da imaginação guiada por papéis, os quais são os principais métodos de tratamento de pessoas que não exercem enfaticamente aos outros (Halpern, 2003).

Segundo Yalom (1995), muitos são os benefícios de um grupo de psicodrama, especialmente àqueles que exigem a integração de compreensão pessoal, empatia e construção de significado. Processos como modelagem, compartilhamento de informações, cultivo de um grau de altruísmo e prestatividade, e a descoberta de suas preocupações, são compartilhadas por outros, os quais adicionam coesão ao grupo e um espírito de otimismo na aprendizagem.

Durante o procedimento da cabine, muitas participantes assustavam ao se verem refletidas no espelho, sendo impactante para muitas. Algumas se elogiavam, entretanto, outras tiveram dificuldade, abaixavam a cabeça como se tivessem se negando a olhar.

O psicodrama proporciona em médio prazo aos participantes o autoconhecimento, que está diretamente relacionado a uma das necessidades básicas, o desejo de aprender e de dar sentido 
às experiências. Isso inclui adquirir o máximo de conhecimento sobre os próprios padrões, preferências e processos. Como em outros domínios, quanto mais profundamente entende-se algo, melhor pode-se dominá-lo (Gottlieb \& Perazzo, 2016)

O autoconhecimento está referido a um tipo particular de conhecimento, geralmente de tipo emocional ou psicológico. Ele é importante por um motivo central, que é oferecer um caminho para maior auto realização. A falta de autoconhecimento deixa a pessoa aberta à acidentes e ambições equivocadas (Skinner, 1990).

Freud (1916) argumentava que o autoconhecimento emancipa o ser humano de ser escravo do inconsciente e de seus muitos caprichos aparentemente irracionais. Somente quando se conhece os padrões e de onde eles vêm, pode-se gerenciá-los com eficácia.

Portanto, o indivíduo pode descobrir se conhecendo melhor que possui atração por um gênero diferente, ou ter ambições profissionais bem diferentes daquelas que a sociedade espera. Logo, as pessoas 'resistem' a descobrir muito sobre si mesmas em muitas áreas, graças aos processos inconscientes (Snowdon, 2012; Cassam, 2014)

Segundo Burge (2011), resistir significa estar escapando da humilhação de admitir apetites e desejos específicos, especialmente quando estes estão em desacordo com o que as pessoas gostariam de ser, ou como os outros querem que elas sejam, reduzindo o sofrimento imediato. Mas o custo é que não se pode apontar adequadamente para o que realmente as fariam felizes.

Por fim, de certo modo, as mulheres apresentaram sinais de que algo havia se modificado internamente a elas, muitas conseguiram se autoconhecer, mostrando serem capazes de se estabelecerem em quaisquer contextos sociais, aos quais demandarem delas o exercício de seus papeis.

\section{CONSIDERAÇÕES FINAIS}

De modo geral, o encontro confirma que devido ao psicodrama ser uma técnica psicoterápica que possui a finalidade de propiciar uma ação dramática no indivíduo, foi através da dramatização que as participantes puderam entrar em contato consigo mesmas e suas estruturas e inter-relações, demonstrando o quanto elas ao se reconhecerem são mais capazes de estabelecer diferentes conexões, em diferentes contextos da sociedade e exercerem seu papel. Confirmando que os recursos psicodramáticos auxiliaram as participantes no resgate às diversas possibilidades de criatividade e ação de emancipação ante aos cenários diferentes que vivem.

Rev. Psicol Saúde e Debate. Dez., 2020:6(2): 328-337. 


\section{REFERÊNCIAS}

Brandão, D. A. L. et al. (2018). Convívio Entre Mães e Filhos e a iniciação ao uso de drogas. Id on Line Revista Multidisciplinar e de Psicologia, 12(40), 512-526.

Burge, T. (2011). Self and self-understanding. The Dewey lectures (2007-2011), The Journal of Philosophy, CVIII/6-7. Reprinted in Cognition through understanding (pp. 140-228). Oxford: Oxford University Press.

Cassam, Q. (2014). Self-knowledge for humans. Oxford: Oxford University Press.

Erigüç G, Kose S. (2013). Avaliação da inteligência emocional e habilidades de comunicação dos candidatos a gerente de saúde: amodelagem de equações estruturais. International Journal of Busi-ness and Social Science, 4, 115-123.

Freire Filho, J. \& Leal, T. (2015). "Mas Por Que, Afinal, As Mulheres Não Sorriem?": Jornalismo E As Razões Da (In)Felicidade Feminina. Ciberlegenda, 33, 8-20.

Freud, S. (1916). Parelleles mythologiques à une representation obsessionnelle plastique. In S. Freud. Essais de Psychanalyse apliquée. (M. Bonaparte \& E. Marty, Trads. Paris : Gallimard

Gottlieb, L., \& Perazzo, S. (Orgs.) (2016). Psicodrama: Apontamentos e criação. São Paulo: FiloCzar.

Halpern J.(2003). What is clinical empathy? J Gen Intern Med. 18(8):670-674

Instituto Brasileiro de Geografia e Estatísitca [IBGE]. (2018). Coordenação de trabalho e rendimento. Pesquisa Nacional por amostra de domicílios contínua: características gerais dos domicílios e dos moradores: 2017. Brasília, DF, 2018. Disponível em: $<$ https://biblioteca.ibge.gov.br/visualizacao/livros/liv101566_informativo.pdf>.

Instituto Brasileiro de Geografia e Estatísitca [IBGE]. (2020). Conheça o Brasil - População.

Moreno, J. L. (2011). Psicodrama. 13ed, São Paulo: Cultrix.

Paes, B. (2016). Acesso à informação e direito das mulheres. São Paulo: Artigo 19 Brasil. Quantidade de homens e mulheres, Disponível em: https://educa.ibge.gov.br/jovens/conhecao-brasil/populacao/18320-quantidade-de-homens-e-mulheres.html

Simões, F. I. \& Hashimoto, F. (2012). Mulher, mercado de trabalho e as configurações familiares do século XX. Vozes dos Vales, 1(2), 1-25.

Skinner, B. F. (1990). Can psychology be a science of mind? American Psychologist, 45(11).

Snowdon, P. (2012). How to think about phenomenal self-knowledge, in Coliva A. (ed), 243-262.

Wechsler, M. P. F. \& Monteiro, R. F. (2016). Psicodrama público na contemporaneidade: cenários brasileiros e mundiais. São Paulo: Ágora.

World Health Organization. (2016). Declaração de Xanghai. Consenso dos Prefeitos de Cidades Saudáveis de Xangai. 9a Conferência Global de Promoção da Saúde, Xangai. Disponível em: https://www.who.int/healthpromotion/conferences/9gchp/shanghai-declaration.pdf. 
Yalom, I. 1995. Teoria e prática da psicoterapia de grupo . 4ª ed. Nova York: Basic Books. 